\title{
Estimation of in vivo digestibility with the laying hen by an in vitro method using the intestinal fluid of the pig
}

\author{
BY K. SAKAMOTO AND T. ASANO \\ Nippon Kayaku Co. Ltd, Takasaki-shi 370-12, Japan \\ AND S. FURUYA* AND S. TAKAHASHI \\ Department of Nutrition, National Institute of Animal Industry, \\ Chiba-shi 280, Japan
}

(Received 9 October 1979 - Accepted 26 November 1979)

\begin{abstract}
I. Dry matter and crude protein (nitrogen $\times 6.25$ ) digestibility of four poultry diets determined by an in vitro method using the intestinal fluid of pigs was significantly correlated with corresponding in vivo digestibility values obtained with hens.

2. The intestinal fluid could be lyophilized and stored for at least $35 \mathrm{~d}$ without losing its activity on digestion.
\end{abstract}

Recently, a new in vitro method was proposed to predict the digestibility of diets for pigs (Furuya et al. 1979). The method is based on a simulation of gastric digestion followed by intestinal digestion. The test substance (food) is first incubated with acid pepsin (EC 3.4.4. I) followed by incubation with intestinal fluid obtained from a pig fitted with a simple cannula in the upper jejunum.

Since the over-all digestive efficiency of the chicken is considered similar to that of other non-ruminant animals (Hill, 1962), the in vitro method could be expected to give a good estimate of the in vivo digestibility of poultry diets. The objective of this study was to compare the in vivo procedure with the in vitro method in determining the digestibility of poultry diets. Also, we examined the activity change of the intestinal fluid when the fluid was lyophilized.

\section{EXPERIMENTAL}

Diets A, B, C and D shown in Table I were used in the present study. For the in vitro determinations each diet was ground in a laboratory mill with a $0.5 \mathrm{~mm}$ screen.

Expt $\mathrm{I}$. The relationships between in vitro and in vivo digestibilities. The in vitro dry matter (DM) and crude protein (nitrogen $\times 6.25$; CP) digestibilities were determined by the method described previously (Furuya et al. 1979). The intestinal fluid was obtained from a pig (host animal) fitted with a simple cannula as described previously except that intestinal contents were centrifuged at $1500 \mathrm{~g}$ instead of $1250 \mathrm{~g}$.

Four White Leghorn hens, weighing $1300-1500 \mathrm{~g}$, fitted with an artificial anus by the method of Ariyoshi \& Morimoto (1956) were used for in vivo digestion determinations. They were housed in individual metabolism cages. The trial consisted of four periods of $7 \mathrm{~d}$ each. The four diets shown in Table I were fed in rotation to each hen. After the $4 \mathrm{~d}$ preliminary feeding, all faeces were collected for the following $3 \mathrm{~d}$, dried in a forced-air oven at $60^{\circ}$, air-equilibrated, ground and sampled for analysis. The in vivo digestibilities of DM and CP were determined by the chromic oxide method.

* For reprints.

0007-I 145/80/073S-26I I $\$ 01.00$ (C) 1980 The Nutrition Society 
Tabie I. Composition of the experimental diets $(\mathrm{g} / \mathrm{kg})$

\begin{tabular}{lcccc} 
& \multicolumn{4}{c}{ Diet } \\
\cline { 2 - 6 } Ingredient & $\mathrm{A}$ & $\mathrm{B}$ & $\mathrm{C}$ & $\mathrm{D}$ \\
Ground maize & $708 \cdot 5$ & $732 \cdot 5$ & $652 \cdot 5$ & $668 \cdot 5$ \\
Soya-bean meal & 150 & 120 & 100 & 120 \\
Fish meal & 100 & 50 & - & 50 \\
Rice bran & - & 50 & 200 & 50 \\
Lucerne meal & 20 & 20 & 20 & 20 \\
Calcium carbonate & - & - & - & 50 \\
Dicalcium phosphate & - & - & - & 30 \\
Tricalcium phosphate & IO & - & - & - \\
Sodium chloride & 5 & 5 & 5 & 5 \\
Vitamin and mineral mixture* & $4 \cdot 5$ & $4 \cdot 5$ & $4 \cdot 5$ & $4 \cdot 5$ \\
DL-methionine & I & I & I & I \\
L-lysine & - & I & I & I \\
Chromic oxide & I & I & I & I \\
Chemical composition & & & & \\
Dry matter & 864 & 856 & 851 & 863 \\
Crude protein (nitrogen $\times 6 \cdot 25)$ & 186 & 160 & 134 & 150
\end{tabular}

* Providing (/kg diet): retinol $6 \mathrm{mg}$, cholecalciferol too $\mu \mathrm{g}$, $\alpha$-tocopherol $20 \mathrm{mg}$, thiamin $4 \mathrm{mg}$, riboflavin $20 \mathrm{mg}$, pyridoxine $4 \mathrm{mg}$, pantothenic acid $8.7 \mathrm{mg}$, nictotinic acid $4 \mathrm{mg}$, choline $276 \mathrm{mg}$, iron $3 \mathrm{mg}$, copper $0.3 \mathrm{mg}$, zinc $25 \mathrm{mg}$, manganese $40 \mathrm{mg}$, iodine $\mathrm{I} \mathrm{mg}$.

Expt 2. Effect of lyophilizing the intestinal fuid on in vitro digestibility. Effect of lyophilizing the intestinal fluid on in vitro DM and CP digestibilities were examined with diets A and $\mathrm{C}$. The intestinal fluid was lyophilized immediately after preparation, stored in a desiccator at room temperature for $35 \mathrm{~d}$, reconstituted in water and then used for in vitro digestibility determinations. The values for DM and $\mathrm{CP}$ were compared with those determined using intestinal fluid stored at $-20^{\circ}$ for $35 \mathrm{~d}$ without lyophilizing.

Chemical analysis. $\mathrm{Cr}_{2} \mathrm{O}_{3}$ was determined colorimetrically using the method of Brisson (1956). DM and CP in the food and faeces were determined by the method of the Association of Official Analytical Chemists (1970).

\section{RESULTS AND DISCUSSION}

Expt $\mathrm{I}$. The relationships between in vitro and in vivo digestibilities. The results shown in Table 2 indicate that the in vitro method gave a good estimate of in vivo digestibility. The following linear regression equations could be fitted to the values for the four tested diets: DM, $Y=\mathrm{I} .06 X-0.032 \mathrm{I}(r$ 0.98, $P<0.05$, residual standard deviation (RSD) \pm 0.008 ); CP, $Y=I_{1} .21 X-0.1731(r 0.99, P<0.05, \mathrm{RSD} \pm 0.008)$, where $Y$ and $X$ are in vivo and in vitro digestibilities respectively. The RSD values of the regression for DM and CP were comparable to the corresponding values obtained in our previous experiment with pigs ( \pm 0.01 I and \pm 0.012 for DM and CP respectively; Furuya et al. 1979).

There was a slight dissimilarity between the two methods. For DM, the in vitro digestibilities tended to be lower than the in vivo values. To overcome biased estimates of digestibility the in vitro method should be standardized with samples of known in vivo digestibility in each in vitro experiment.

Expt 2. Effect of lyophilizing the intestinal fluid on in vitro digestibility. The results are given in Table 3. Lyophilizing the intestinal fluid and storing àt room temperature for at least $35 \mathrm{~d}$ had no effect on the digestibility of DM and CP compared with values determined with intestinal fluid stored at $-20^{\circ}$ for $35 \mathrm{~d}$. Previously we showed that the intestinal fluid 
Table 2. Expt I. The relationships between in vitro and in vivo digestibilities of dry matter and crude protein (nitrogen $\times 6.25$ ) in the experimental diets*

(Mean values with their standard errors for eight (dry matter) and four (crude protein) measurements (in vitro) and four hens (in vivo))

Digestibility of:

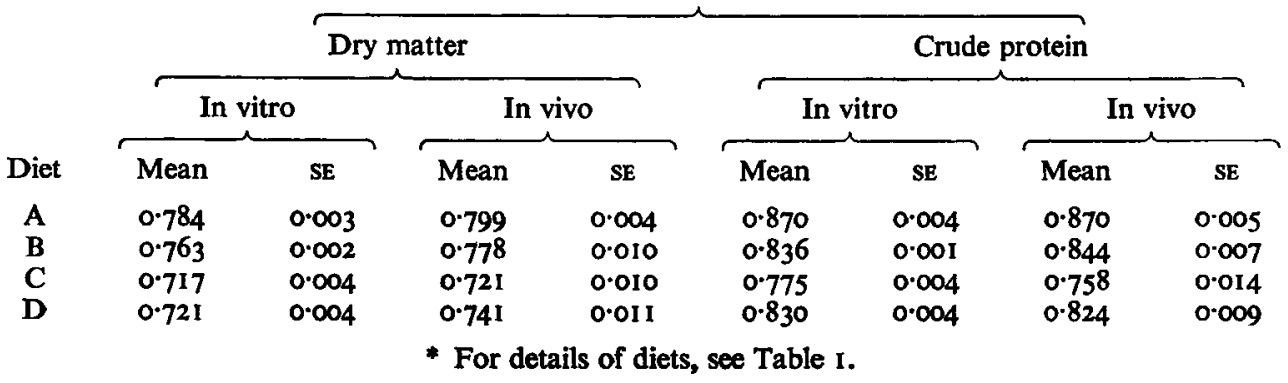

Table 3. Expt 2. Effect of lyophilizing the intestinal fluid on in vitro dry matter and crude protein (nitrogen $\times 6 \cdot 25$ ) digestibility in diets $A$ and $C^{*}$

(Mean values with their standard errors for six (dry matter) or three (crude protein) measurements)

Digestibility of:

$\begin{array}{ccccccccc}\text { Diet } & \overbrace{\text { Mean }}^{\text {Frozen }} & \text { SE } & \overbrace{\text { Mean }}^{\text {Dry matter }} & \text { SE } & \overbrace{\text { Mean }}^{\text {Frozen }} & \text { SE } & \overbrace{\text { Mean }}^{\text {Lyophilized }} & \text { Srude protein } \\ \text { A } & 0.779 & 0.009 & 0.772 & 0.002 & 0.860 & 0.009 & 0.859 & 0.002 \\ \text { C } & 0.712 & 0.004 & 0.714 & 0.003 & 0.766 & 0.004 & 0.769 & 0.004\end{array}$

- Before use, portions of intestinal fluid were either frozen, $-20^{\circ}$, for $35 \mathrm{~d}$ or lyophilized and stored in a desiccator at room temperature for $35 \mathrm{~d}$. For details of diets, see Table $\mathrm{r}$.

can be preserved at $-20^{\circ}$ for at least $60 \mathrm{~d}$ without any obvious change in its activity for DM and CP digestion (Furuya et al. 1979 ).

These results indicate that this in vitro method is not species-specific to the host animal species, but yields reasonable digestibility estimates for species as dissimilar as pigs and chickens. Therefore, this method may be applicable to most non-ruminant animals. Also since lyophilization of the intestinal fluid does not alter its efficiency in the digestion determinations, the use of this in vitro method does not require the maintenance of a host animal in each laboratory.

The authors thank Dr K. Kameoka for supervision, and Dr D. Kubota for reading the manuscript. They also thank Dr Nancy R. Stevenson, C.M.D.N.J. - Rutgers Medical School, for her valuable comments on the manuscript and her help with the English language.

\section{REFERENCES}

Ariyoshi, S. \& Morimoto, H. (1956). Bull. natl Inst. agric. Sci. Gr2, 37.

Association of Official Analytical Chemists (1970). Official Methods of Analysis, 1 ith ed. Washington, DC: Association of Official Analytical Chemists.

Brisson, G. J. (1956). Can. J. agric. Sci. 36, 210 .

Furuya, S., Sakamoto, K. \& Takahashi, S. (1979). Br. J. Nutr. 4I, 511.

Hill, F. W. (1962). In Nutrition of Pigs and Poultry, pp. 3-1 7. [J. T. Morgan and D. Lewis, editors]. London: Butterworths. 